\title{
Prototyping and testing of composite riser joints for deepwater application
}

\author{
Yu Chen', Ralf Seemann ${ }^{2}$, Dieter Krause ${ }^{2}$, Tong-Earn Tay' and \\ Vincent BC Tan'
}

(SAGE

\begin{abstract}
The high strength to weight ratio, good corrosion resistance, and excellent fatigue property make carbon fiber-reinforced plastics a competitive material solution to replace steel in deepwater riser application. In this work, scaled-down composite riser joints were fabricated using a filament-winding machine. The prototypes comprise several carbon fiberreinforced plastic layers wound over an aluminum liner. They consist of a middle tubular section and two metalcomposite interface end fittings for the transfer of load between joints. A series of mechanical tests, including tension and combined tension-bending loading tests were performed to characterize their structural capacity and evaluate the improvement in performance over a purely metallic mandrel. In addition, finite element analyses incorporating elasticplastic properties of the metallic liner, interfacial failure, and complex carbon fiber-reinforced plastics failure modes were carried out. The numerical predictions are in good agreement with the experimental measurements. The experimentally verified FE framework was then extended to design and analyze a full-scale composite riser model for performance prediction to accelerate the application of composite risers by shortening product development cycle and reducing prototyping costs.
\end{abstract}

\section{Keywords}

Deep sea oil riser, marine composites, filament winding, trap-lock end fitting, multi-axial testing

\section{Introduction}

The riser plays an important role in offshore industry for transporting oil and gas from the subsea wellhead to production platforms on the surface. Its capacity and performance directly affect the economic efficiency of oil fields. The riser is a long tubular structure consisting of many identical segments or riser joints. A tension is applied at the top of the riser string to minimize deflection and vibration and to prevent compression at the bottom as the slender structure is disposed to buckling and subsequent catastrophic failure. For conventional steel risers, the required top tension is very high in deepwater and ultra-deepwater environments because of the high self-weight steel that is exacerbated with increasing depth. The high density is an obstacle to ultra-deep water oil exploration. ${ }^{1}$ In order to push the boundaries toward deeper offshore oil exploration, novel lightweight design solutions for oil risers are required.

Carbon fiber-reinforced polymers (CFRP) are well established as lightweight material in the aerospace as well as other transportation industries. Currently, it attracts increasing attention from the offshore industry as a promising material solution for risers due to its high strength to weight ratio compared to traditional metallic materials. ${ }^{2}$ Besides their structural advantage, CFRP has better thermal insulation, corrosion, and fatigue resistance, making their application for risers even more attractive. Utilizing CFRP for riser application would benefit oil platforms in many ways. For example, risers made of CFRP would require much

\footnotetext{
'Department of Mechanical Engineering, National University of Singapore, Singapore

${ }^{2}$ Institute of Product Development and Mechanical Engineering Design, Hamburg University of Technology, Hamburg, Germany

\section{Corresponding author:}

Vincent BC Tan, Department of Mechanical Engineering, National University of Singapore, 9 Engineering Drive I, Singapore II7575.

Email: mpetanbc@nus.edu.sg
} 
lower top-tension load. The decrease in tension load will translate to cost saving by using smaller tensioner and decreasing platform size and mooring systems. ${ }^{3}$ In addition, the light weight of CFRP risers would also reduce the cost associated with offshore transportation and installation. The excellent fatigue resistance of CFRP would also allow for a longer service life compared with traditional steel risers, reducing the costs for maintenance and replacement.

Figure 1 shows a typical composite riser configuration with structural details of the joints. The riser behaves as a long cable with many segmental joints connected together through flange-bolt, clamp, and thread. Within each joint, the middle tubular body is attached to the end connector via the so-called metalcomposite interface (MCI) end fitting. The end fitting is critical for load transfer between the standard connector and the middle joint body. A reliable end fitting is as vital as, if not more important than, the middle tubular body. ${ }^{4}$

Although there are numerous advantages associated with CFRP, it also presents many challenges in design, modeling, manufacturing, testing, and qualification compared with traditional metallic materials. Over the past few decades, there have been numerous studies trying to overcome these challenges.

In the 1980s, the Institut Francais du Petrole (IFP) and Aerospatiale of France first evaluated a composite joint for their application in offshore industry. 5,6 The riser was designed for a concrete Tension-Leg Platform (TLP) for depths within the 500-1000 $\mathrm{m}$ range. The riser consists of internal and external buna liners, helical wound carbon fiber layers $\left( \pm 20^{\circ}\right)$, and hoop wound glass fiber layer $\left(90^{\circ}\right)$. Burst, axial tension, tensile fatigue, and creep tests were carried out. The tensile fatigue tests demonstrated that the riser has sufficient fatigue resistance, surviving three times the number of cycles that would fail a steel riser. In 1995, a joint industry project, supported by the US National Institute of Standards and Technology (NIST) Advanced Technology Program (ATP), was established to design, fabricate, test, and qualify a composite riser. ${ }^{7-10}$ This project targeted water depths of 900-1500 m. Both single and dualcasing risers were considered. The ATP composite riser had a more complex composition than in the previous IFP project. It was constructed with carbon/glass hybrid hoop layers in addition to carbon helical layers and glass hoop layers. Numerous axial tension, burst, collapse,

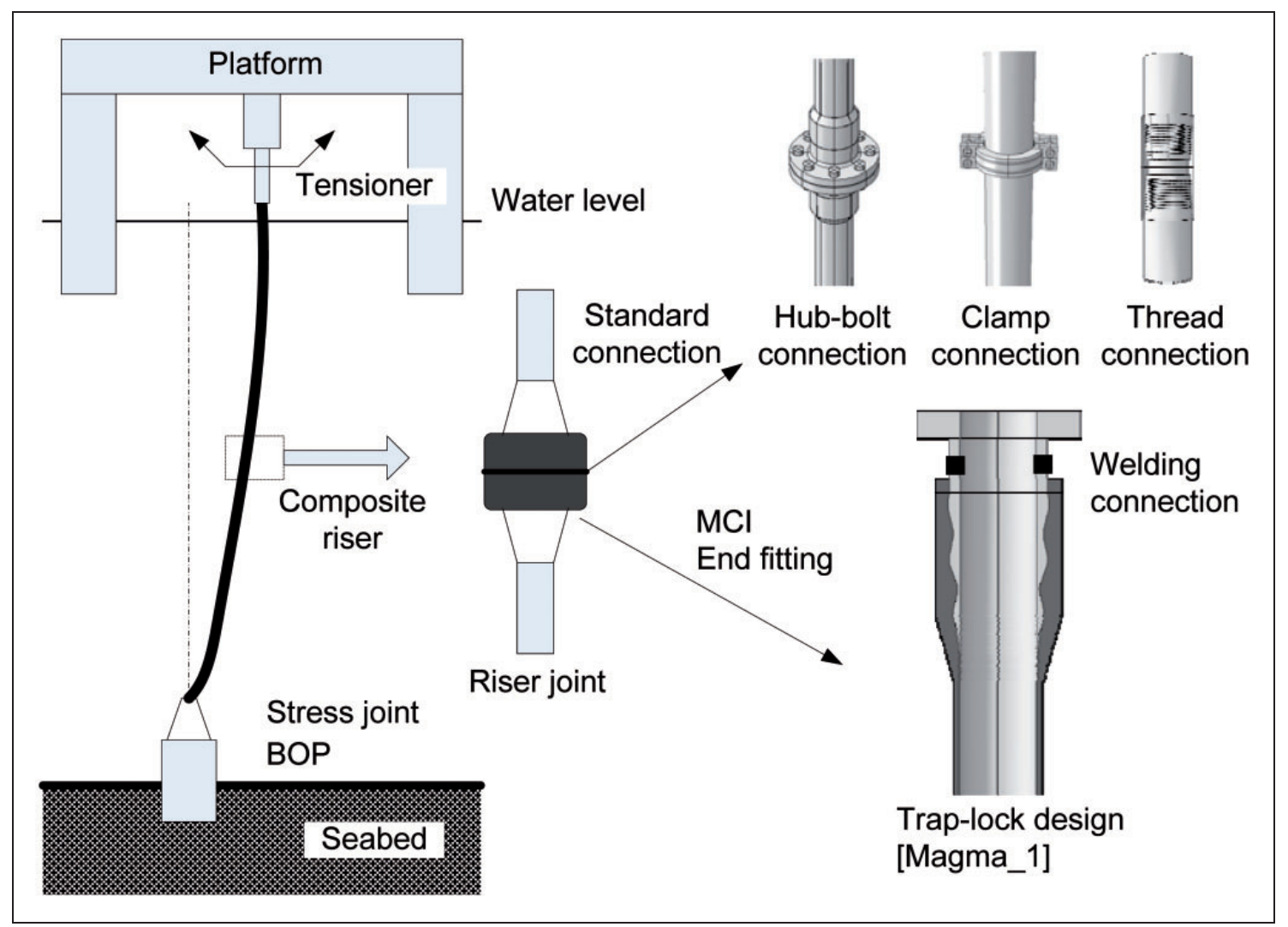

Figure I. Typical configuration of composite risers. 
static fatigue, and impact tests were performed on 90 prototypes. It is worth mentioning that the trap-lock end fitting for thermosetting composite risers was patented in the course of this project. ${ }^{11}$ Following the NIST-ATP project, ConocoPhillips and Kvaerner contracted Lincoln Composites (USA) to design a drilling riser joint featuring a thin full-length titanium liner. The joint was designed to fit into the existing riser string of Statoil's Heidrun platform in the North Sea with the intent of field demonstration. In 2001, the riser joint was placed in service, and it was proven successful. ${ }^{12}$ After that, the next-generation design tried to replace titanium with steel as the liner material. Several composite production risers were developed to satisfy the same requirements as conventional steel risers on the Magnolia TLP in the Gulf of Mexico at a water depth of about $1560 \mathrm{~m}$. The goal was to replace a few steel joints with prototype composite joints to gain in situ experience and data. However, the riser did not proceed to installation due to welding problems at the transition region between end fitting and connector. It should be noted that the failure of the composite risers was not due to the composite material, but to the steel liner inside the composite and their welding connection to the connector. ConocoPhillips still considered this technology highly promising. ${ }^{13}$ In 2009 , with sponsorship from NIST/ATP program, the University of Texas conducted a collapse pressure test on a full-scale diameter composite drilling riser prototype. ${ }^{14}$ The tube was subjected to external water pressure up to collapse, providing a basis for verification and calibration of analytical estimates of the collapse pressure of large-scale carbon fiber tubes. The test specimen was fabricated with an unintended initial delamination caused by the breakdown of the filament-winding machine. The results showed that the delamination between composite layers determined the collapse pressure. This emphasizes the importance of following strict manufacturing protocols when composite materials are used. From 2008 to 2011, Research Partnership to Secure Energy for America sponsored a project on composite risers, in which full diameter prototypes demonstrated manufacturability and sufficient margins of safety with respect to burst strength, bending fatigue, and tolerance to dropped object impact damage. ${ }^{2}$ The design employed a steel liner, and it confirmed that a potential weight savings of $40-50 \%$ could be achieved in comparison to an all steel construction. More recently, Magma (UK) developed a new solution for composite risers using thermoplastic polymer and carbon fiber. ${ }^{4,5}$ The composite matrix is a high-performance thermoplastic polymer-polyether ether keton. It has good thermal stability and withstand above $200^{\circ} \mathrm{C}$. This material not only has good structural strength but also exhibits superior behavior in corrosion, fatigue, chemical resistance, ageing, and permeation. Over 1000 specimens were subjected to tension, bending, compression, collapse, impact, and fatigue tests to demonstrate the feasibility and reliability of this material system and relevant end-fitting designs. There are ongoing efforts to make composite risers gain further acceptance by the industry.

The novelty of the present study is the development of a FE-framework for the prediction of the mechanical performance of the MCI and its validation through comprehensive multiaxial tests. Material selection, mandrel design, and fabrication procedure are introduced, followed by a description of a specialized hydraulic Hexapod test rig used for the mechanical characterization of the prototypes. Details of the finite element (FE) modeling are also presented. The tensile-bending failure envelopes determined from experiments results and computational predictions are compared to validate the FE calculations before extending the FE modeling framework to analyze fullscale composite risers. Finally, concluding remarks and suggestions for future development are provided.

\section{Prototyping composite risers}

\section{Material selection}

CFRPs have two basic constituents - a polymeric matrix and carbon fibers. Viscosity and pot life are two important considerations in the selection of polymers for the matrix from the viewpoint of fabrication. Epoxies with ultra-high viscosity are not suitable for filament winding as they are difficult to fully wet carbon fiber filaments resulting in void defects and air traps. High viscosity would also lead to high tension within the filament due to high-viscous drag force when the filaments pass over guiding rollers. In addition, it is necessary to ensure that the pot life of the chosen epoxy is longer than the fabrication process, which typically lasts several hours or longer.

The epoxy system used in this study is Epicote 1002 FW (Polymer Technologies Pte Ltd, Singapore). ${ }^{15}$ It is a combination of liquid bisphenol-A, epichlorhydrin epoxide resin, amine, and polymeric additives. It has a medium viscosity and a pot life of $10 \mathrm{~h}$. The glass transition temperature is $150^{\circ} \mathrm{C}$. It requires oven curing for one hour under $80^{\circ} \mathrm{C}$ followed by four hours under $150^{\circ} \mathrm{C}$ as suggested by the supplier. The carbon fiber roving used in this work is T700SC-12K (Toray, Japan).

\section{Mandrel sizing}

Scaled-down composite risers are prototyped instead of full-scale specimens. In order to ensure that the overall strength of the prototypes is within the testing capacity of existing facilities, preliminary calculations were 
performed to determine the size and material of the mandrel as well as thickness of the composite layer and its layup.

Figure 2 shows the drawing of the aluminum mandrel. This mandrel has a tubular middle section with an inner diameter (ID) of $54 \mathrm{~mm}$, a length of $180 \mathrm{~mm}$, and a thickness of $2 \mathrm{~mm}$. At both ends of the tubular middle section are the trap-lock end fittings. The fittings are specially contoured for the effective load-transfer between the metallic component and the composite laminate. The mandrel is machined with connection sections at the ends for clamping the prototype to the specimen mount of the testing facilities. The connection section is thick enough to ensure that any structural damage during mechanical tests occurs only within the region of interest - the middle tubular section and trap-lock sections. The 16 pins attached to each end of the mandrel help to anchor the carbon filaments during the winding process. They are removed after the matrix is cured.

It is worth mentioning that the material for the inner lining (mandrel), aluminum alloy $6061 \mathrm{~T} 6$, is chosen for the prototypes due to its favorable collective properties at reasonable cost. Its low density enables good handling of the prototypes. The comparably low strength enables the dimensioning of the structure as a whole according to the available testing capabilities mainly through the filament wound composite layers. In actual oil riser applications, the liner is likely to be made of a more suitable alloy with regards to thermal mismatch of the materials. However, it is assumed that the structural behavior of the MCI, which is of primary concern in the present study, is transferable to other material combinations.

\section{Filament-winding fabrication}

Filament winding is the only technique employed in previous joint industry projects. It is particularly suitable for fabricating long tubular pipes and vessels. In filament winding, the mandrel is continuously rotated while a carriage reciprocates up and down its entire length and in the process lays fibers wetted by epoxy in various patterns to give helical and radial plies.

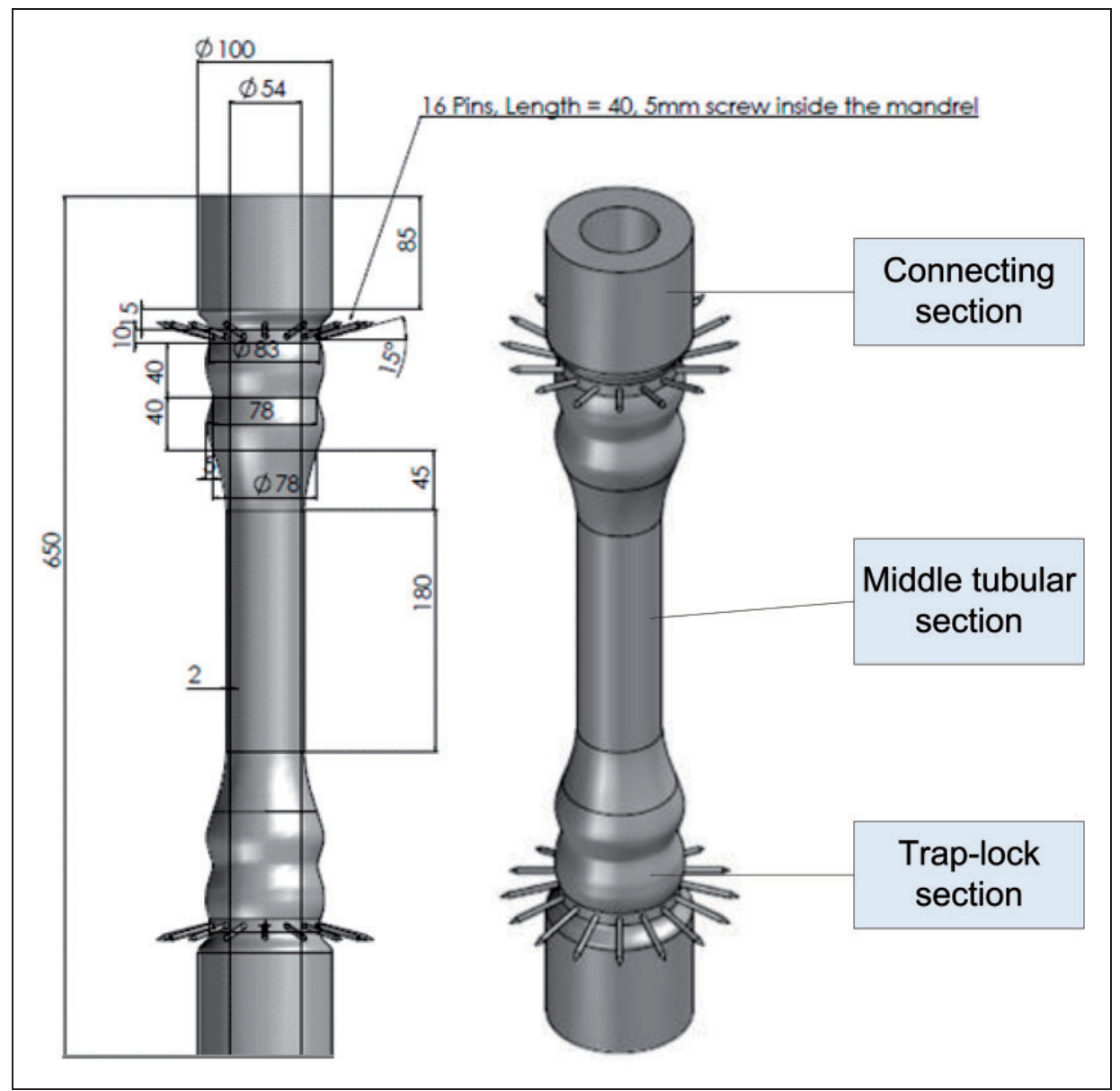

Figure 2. Drawing of aluminum mandrel. 
Helical plies enhance both axial and hoop strengths while radial plies mainly improve hoop strength for high pressure applications. An appropriate winding angle layup should be carefully designed and optimized to achieve the balance between axial tensile capacity and pressure resistance. Once the desired plies are wound, the product is then subjected to oven curing. Sometimes, room temperature curing is adopted depending on the epoxy system.

In filament-winding production, the mandrel is normally removed, leaving the hollow composite tube. However, in this work, the metallic mandrel is left inside to function as the liners in full-scale risers. Liners serve as an anti-abrasion layer and improve water tightness. A four-axis CNC filament-winding machine from Mikrosam is used. The wound composite layer consists of 10 plies in total with a layup sequence of $[90 / 15 /-15 / 90 / 50 /-50 / 50 /-50 / 50 /-50]$. The thickness of each composite ply is $2.2 \mathrm{~mm}$, calculated from averaging all specimens. Finally, it is worth mentioning that in order to conduct small angle winding, anchoring pins are fixed at the end of the trap-lock section to avoid pulling back of the filament as schematically illustrated in Figure 3(b). These pins are cut after oven curing.

\section{Experimental setup for mechanical characterization}

Due to self-weight and the drag induced by the flow of seawater, riser joints are subjected to high tension and bending moments as well as internal and external pressures. In this paper, scaled-down prototypes are subjected to a series of mechanical tests, including pure tension and combined loading tests as detailed in the following sections.

\section{Tensile test}

Uniaxial tensile tests are carried out on a standard Shimadzu testing machine equipped with a $250-\mathrm{kN}$ load cell. The riser prototype is connected to the machine fixture via two threaded bars as shown in Figure 4. An upward displacement is applied at a

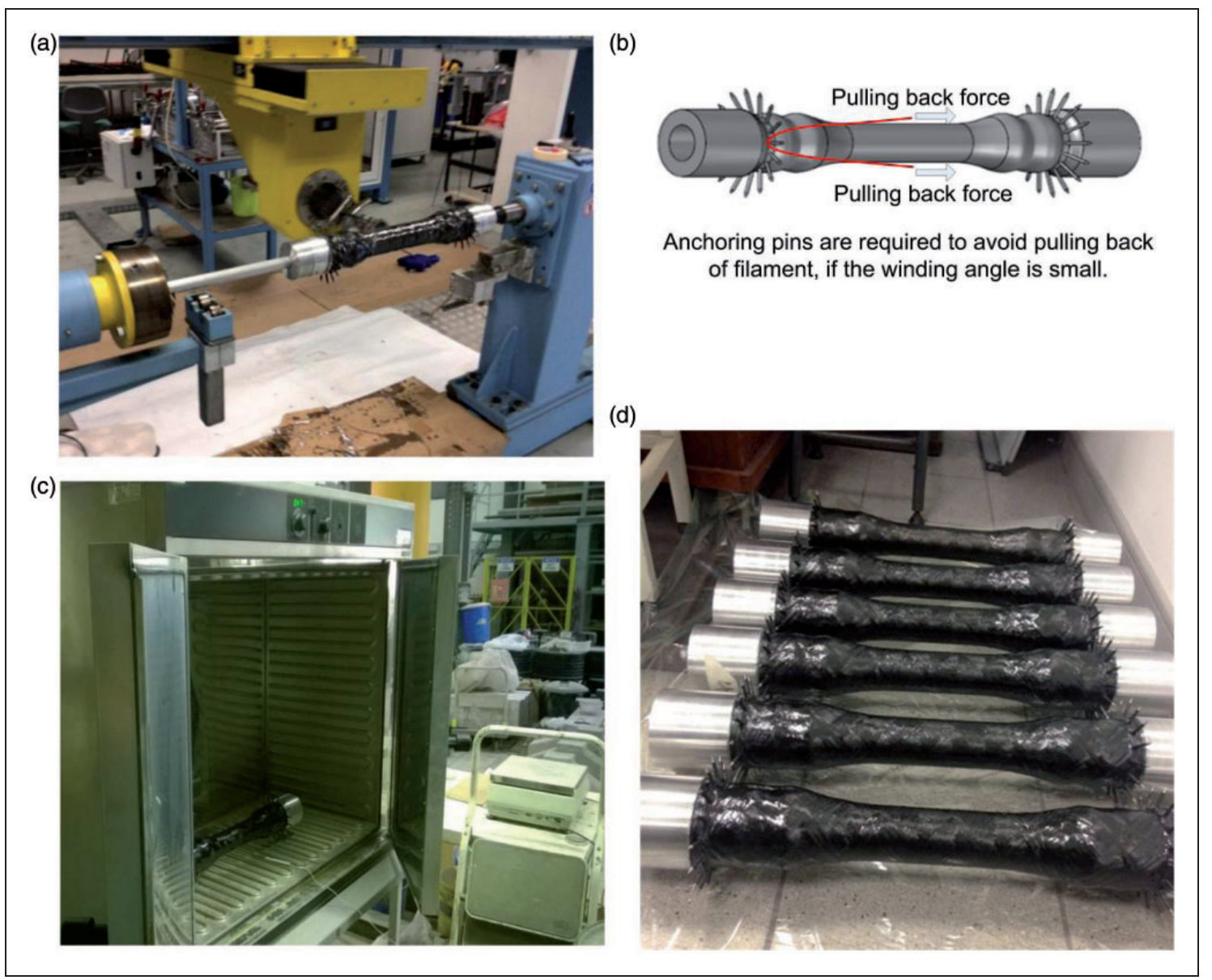

Figure 3. (a) Four-axis filament winding machine, (b) small angle winding illustration, and (c) ovens. 
speed of $1 \mathrm{~mm} / \mathrm{min}$, which can be regarded as a quasistatic process. Axial strains are measured via linear strain gauges placed at the center of the tubular middle section.

\section{Combined loading tests using a six DOF test rig}

Combined tensile-bending loading tests are performed using a custom-designed multi-purpose Hexapod testing facility at Technische Universität HamburgHarburg, Germany. The facility is based on the Stewart platform principle using six hydraulic cylinders that move a 2.5-ton ring structure. This setup allows for arbitrary load introduction using all translational and rotatory degrees of freedom (DOF), which can be measured using a customized six DOF load cell placed underneath the Hexapod ring. The load cell has a measuring range of $250 \mathrm{kN}$ in axial direction, $150 \mathrm{kN}$ in lateral direction, and $40 \mathrm{kNm}$ in all rotatory DOFs. The test rig control system allows both force control and displacement control to be applied simultaneously on separate DOFs.

For the combined loading tests, two $20-\mathrm{mm}$ steel fixture plates are clamped at the top and bottom of the riser prototypes using threaded bolts, which are screwed axially into the clamping region of the mandrel. The upper fixture plate is attached to the Hexapod ring, while the lower fixture plate is mounted on the six DOF load cell. On each test specimen, eight linear strain gauges (HBM 1-LY18-6/120) are placed along the axial direction circumferentially at two height levels of the tubular middle section. In addition, a 3D optical deformation analysis system (GOM ARAMIS) equipped with two $5 \mathrm{MP}$ cameras is used to capture the strains on a section of the prototype surface, using digital image correlation (DIC). The internal 6 DOF displacement measurement of the Hexapod is complemented by three circumferential external laser displacement sensors $(2 \times$ Micro Epsilon optoNCDT 1402-200 with $13 \mu \mathrm{m}$ resolution and $1 \times$ Micro Epsilon optoNCDT $1630-20$ with $1 \mu \mathrm{m}$ resolution). These directly measure the relative axial displacement of the two fixture plates attached to the specimen. This allows for the tracking of possible imperfections in the tensile load introduction. Last, two microphones are placed about two meters from the specimen in order to record the cracking of the material at the onset and progression of failure. In total, more than 25 data channels are logged synchronically during the test runs. Figure 5 illustrates the test set up details. A similar setup using the same testing facility has been successfully applied to characterize the influence of imperfections on the buckling of CFRP shells. ${ }^{16}$

In combined tension and bending tests, the loads are applied in two sequential steps. First, a pretension is applied at a displacement rate of $1.5 \mathrm{~mm} / \mathrm{min}$ until a predefined axial load is attained. This load is maintained through force control while the Hexapod ring is rotated around the intersection of the riser axis and the top of the load cell at a rate of $1.2^{\circ} / \mathrm{min}$, thus applying a bending load to the structure up until total failure. In total, four composite riser prototypes are tested in

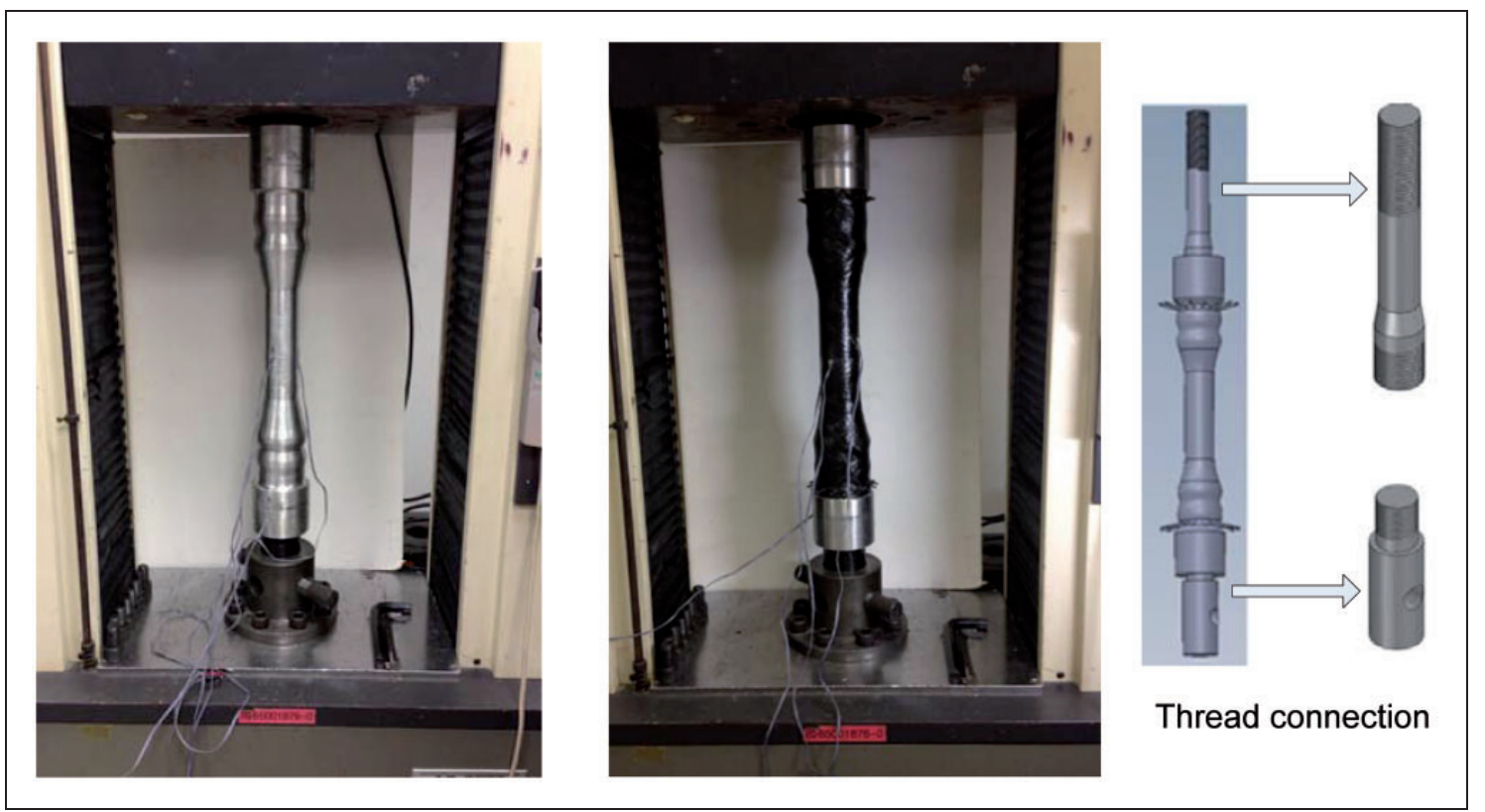

Figure 4. Experimental setup of tensile tests. 


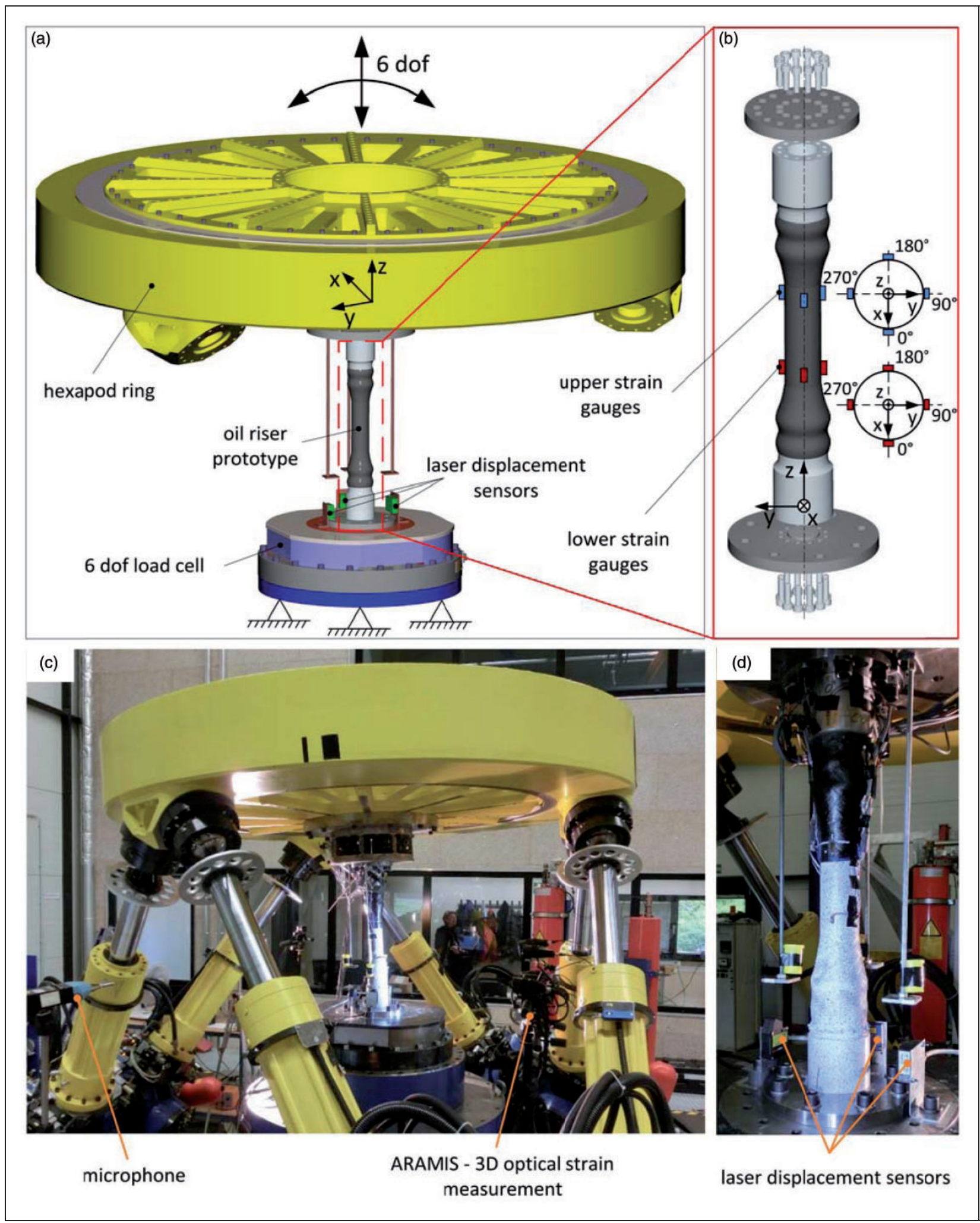

Figure 5. (a) Schematic test setup, (b) mounting of composite risers using fixture plates and position of strain gauges, (c) test setup in the hexapod facility, and (d) close-up of the clamped oil riser, with sprinkle pattern for the 3D DIC measurement on the lower half of the specimen. 
the Hexapod facility. Each test is performed with a different force-controlled pretension $(0 \mathrm{kN}, 50 \mathrm{kN}$, $100 \mathrm{kN}, 150 \mathrm{kN})$. As a control group, two aluminum mandrels were tested under 0 and $50 \mathrm{kN}$ pretension.

When rotating the Hexapod ring, not only bending moments are induced in the specimen, but a shear force is also set up at the clamps. The control system of the Hexapod is capable of negating the shear by simultaneously translating the ring as it rotates so that the riser joint is under uniform tension and bending. However, in order to cause failure, the required rotation angle of the Hexapod ring will have to be greater than the machine limit of about $8^{\circ}$ for tests with low tension levels. For low tension tests, the shear force $F_{x}$ is not negated. The shear force causes a bending moment distribution along the riser span. The actual bending moment experienced by the specimen is the sum of the bending moment measured at the load cell and the amount contributed by the lateral force (Figure 6).
This leads to considerably higher bending moments at the bottom clamp, which enables us to test specimen until failure when there is low or no tension applied. However, there are also two shortcomings. First, the bending moment is no longer constant along the riser span. It is greatest at the bottom end of the specimen and decreases along the riser span with increasing distance from the base (Figure 6). Second, the riser prototype is not only subjected to tension and bending moment, but also lateral shear although it is noted that shear forces generate stresses that are generally an order of magnitude smaller than the bending stresses.

\section{FE simulation}

Apart from mechanical characterization through experiments, FE models were also constructed to estimate the structural performance of these prototypes. CFRP is technically more complex than metallic

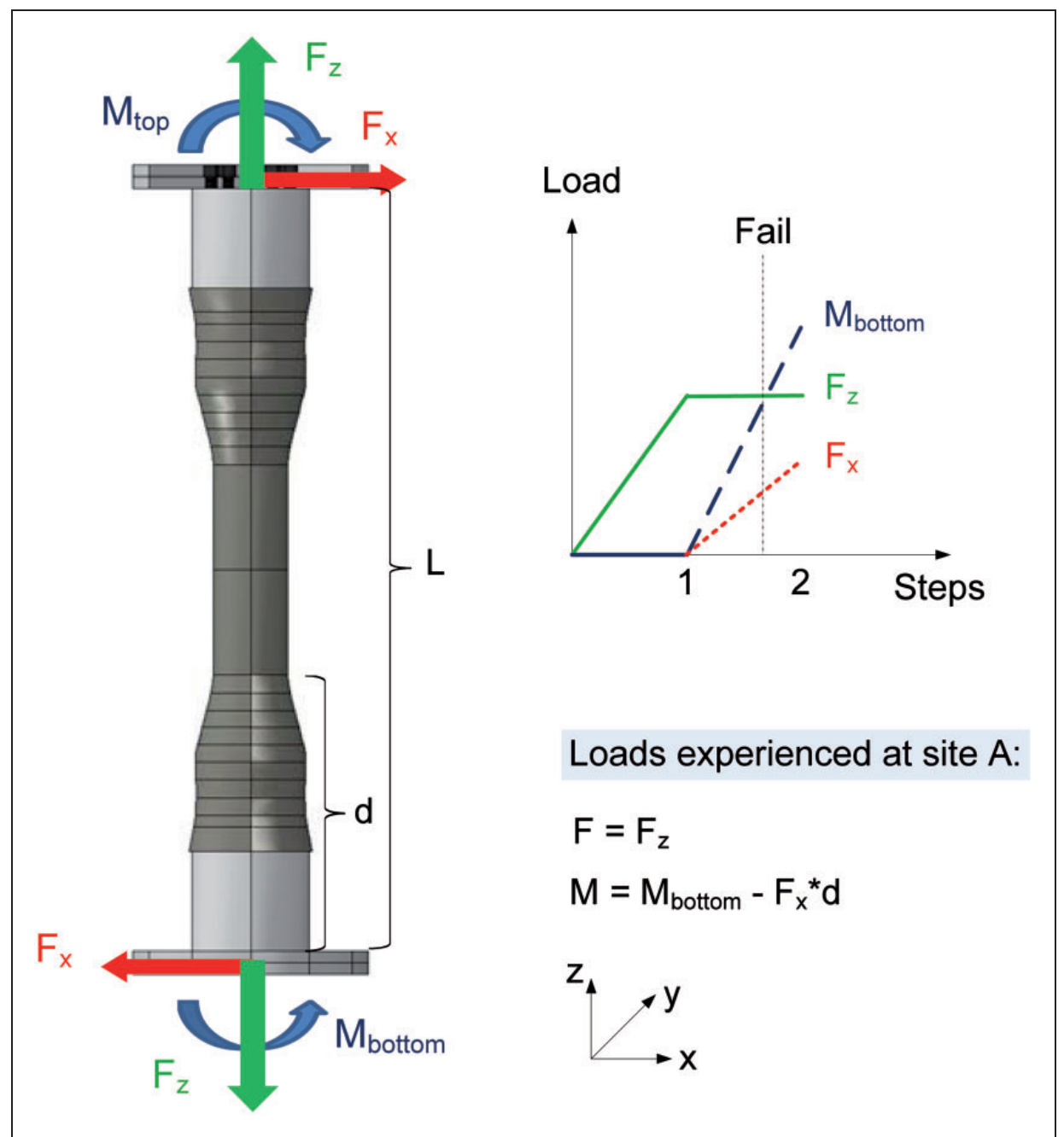

Figure 6. Schematic illustration of combined loading in the hexapod test rig. 
materials due to its anisotropic properties. The situation is even more complex when they are interfaced with metallic components because metal-composite interface present particular challenges for numerical modeling. ${ }^{4}$ In this work, a FE model was developed that incorporates the elastic-plastic properties of the metallic liner, a cohesive surface for the metalcomposite interface, and a damage model to describe the failure of CFRP. To reduce the computational time, only half the riser is considered due to structural symmetry. The bottom is fixed in the axial direction and free in the in-plane directions. Tension and bending are applied by kinematic coupling of reference point with the top plate.

Specifically, the liner is modeled as elastic-plastic using the material properties of the aluminum 6061 T6, ${ }^{17}$ as shown in Figure 7(c). The interface between composite laminate and metallic liner is modeled using a cohesive surface, which is able to simulate splitting separation governed by a traction-separation law. ${ }^{18}$ Interfacial damage initiation is based on a stress-based quadratic criterion, and it is dominated by the nominal stress $t_{n}$ as well as shear stresses $t_{s}$ and $t_{t}$ as follows

$$
\left\{\frac{t_{n}}{S_{n}}\right\}^{2}+\left\{\frac{t_{s}}{S_{s}}\right\}^{2}+\left\{\frac{t_{t}}{S_{t}}\right\}^{2}=1
$$

In equation (1), $S_{n}, S_{s}$, and $S_{t}$ are the tensile and shear strengths of cohesive bonding. They are set to be $25 \mathrm{MPa}$ in this work as experiments show the tensile and shear strengths of aluminum-epoxy interfaces range from 20 to $35 \mathrm{MPa} .{ }^{19}$

For CFRP, a damage model based on the Hashin failure criteria ${ }^{20}$ is implemented using the subroutine
USDFLD in Abaqus. In the theory, four failure modes are accounted for as described below.

Mode 1: Tensile fiber failure for $\sigma_{11} \geq 0$

$$
\left(\frac{\sigma_{11}}{X_{T}}\right)^{2}+\frac{\sigma_{12}^{2}+\sigma_{13}^{2}}{S_{12}^{2}}= \begin{cases}\geq 1 & \text { failure } \\ <1 & \text { no failure }\end{cases}
$$

Mode 2: Compressive fiber failure for $\sigma_{11}<0$

$$
\left(\frac{\sigma_{11}}{X_{C}}\right)^{2}= \begin{cases}\geq 1 & \text { failure } \\ <1 & \text { no failure }\end{cases}
$$

Mode 3: Tensile matrix failure for $\sigma_{22}+\sigma_{33}>0$

$$
\begin{aligned}
& \frac{\left(\sigma_{22}+\sigma_{33}\right)^{2}}{Y_{T}^{2}}+\frac{\sigma_{23}^{2}-\sigma_{22} \sigma_{33}}{S_{23}^{2}}+\frac{\sigma_{12}^{2}+\sigma_{13}^{2}}{S_{12}^{2}} \\
& \quad=\left\{\begin{array}{cl}
\geq 1 & \text { failure } \\
<1 & \text { no failure }
\end{array}\right.
\end{aligned}
$$

Mode 4: Compressive matrix failure for $\sigma_{22}+\sigma_{33}<0$

$$
\begin{aligned}
& {\left[\left(\frac{Y_{C}}{2 S_{23}}\right)^{2}-1\right]\left(\frac{\sigma_{22}+\sigma_{33}}{Y_{C}}\right)+\frac{\left(\sigma_{22}+\sigma_{33}\right)^{2}}{4 S_{23}^{2}}} \\
& \quad+\frac{\sigma_{23}^{2}-\sigma_{22} \sigma_{33}}{S_{23}^{2}}+\frac{\sigma_{12}^{2}+\sigma_{13}^{2}}{S_{12}^{2}}=\left\{\begin{array}{cl}
\geq 1 & \text { failure } \\
<1 & \text { no failure }
\end{array}\right.
\end{aligned}
$$

where $\sigma_{\mathrm{ij}}$ denotes the stress components. $X_{T}$ and $Y_{T}$ denote allowable tensile strengths while $X_{C}$ and $Y_{C}$ denote allowable compressive strengths in the respective material directions. $S_{12}, S_{13}$, and $S_{23}$ are the shear strengths in the principal material directions. When first

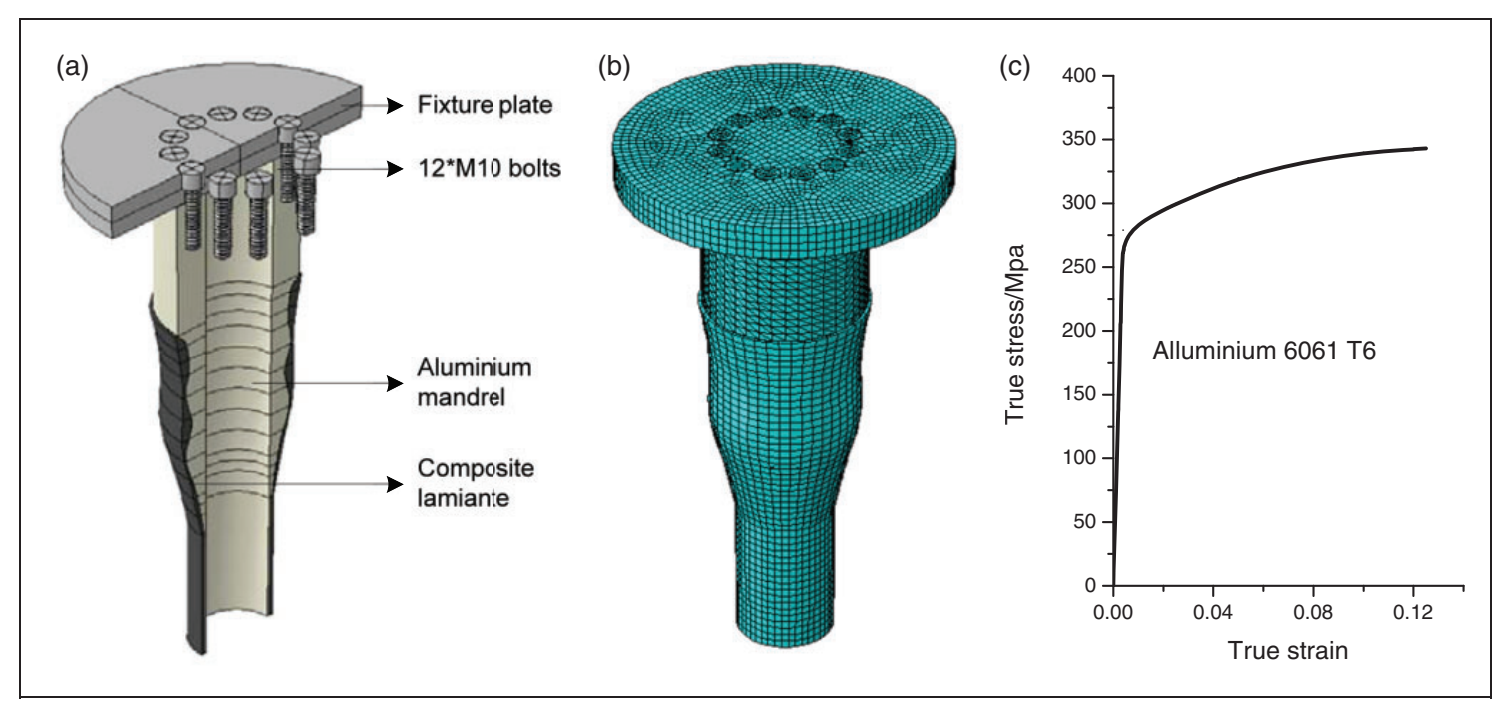

Figure 7. (a) Geometrical model and thread connection, (b) meshed model, and (c) stress-strain curve of aluminum $606 \mathrm{I}$ T6. ${ }^{17}$ 
ply failure (Mode 3 and Mode 4) occurs, the damaged element can still bear considerable load as the load is transferred to other plies. Only when last ply failure (Mode 1 and Mode 2) occurs, the element is regarded as complete failure.

The fiber orientation in the simulation model is simplified in a way that the layup sequence of the filament wound as described earlier is directly transferred to the FE model, thus neglecting the fact that the actual fiber angles deviate locally in the trap lock section due to the contour curvatures. However, this deviation is assumed to be minor with limited effect on the global structural response of the prototype.

Table 1 summarizes the elastic material parameters and strength values of CFRP as used in the present numerical study. It should be noted that the composite layers are wound in-house, and it is difficult to characterize their mechanical properties with standard tests. Therefore, their elastic moduli and strengths are adopted from available literature. ${ }^{21}$ The volume

Table I. Elastic constants and strengths of CFRP.

\begin{tabular}{lll}
\hline CFRP: elastic moduli & \\
\hline$E_{11}=114.75 \mathrm{GPa}$ & $E_{22}=8 \mathrm{GPa}$ & $E_{33}=8 \mathrm{GPa}$ \\
$G_{12}=3.8 \mathrm{GPa}$ & $G_{13}=3.8 \mathrm{GPa}$ & $G_{23}=2.7 \mathrm{GPa}$ \\
$v_{12}=0.27$ & $v_{13}=0.27$ & $v_{23}=0.49$ \\
CFRP: tensile, compressive and shear strengths \\
\hline$X_{T}=158 \mathrm{IMPa}$ & $Y_{T}=Z_{T}=76 \mathrm{MPa}$ & $X_{C}=1249.5 \mathrm{MPa}$ \\
$Y_{C}=Z_{C}=85 \mathrm{MPa}$ & $S_{12}=S_{23}=S_{13}=98 \mathrm{MPa}$ & \\
\hline
\end{tabular}

fraction of carbon fiber in the current work is $51 \%$, which is slightly lower than that of CFRP manufactured from pre-pregs where volume fraction is around $60 \%$. Therefore, the elastic constant $E_{11}$, tensile strength $X_{T}$, and compressive strength $X_{C}$ are proportionally scaled down, assuming that the stiffness and strength of CFRP are largely dominated by the fiber content in the principal direction.

\section{Results and discussion}

\section{Tensile tests}

Figure 8 shows the force-displacement curves of a composite riser joint in comparison with an aluminum mandrel. The aluminum specimen yielded at a tension of about $100 \mathrm{kN}$. After the yield point, with further deformation, the tensile load increases slightly on account of strain hardening until it reaches the ultimate tensile strength (UTS) of $107 \mathrm{kN}$. The aluminum specimen ruptures at the middle tubular section as seen in Figure $8(\mathrm{~b})$. For the composite riser, the tensile load increases proportionally with displacement and becomes non-linear in later stage. It shows several small drops before the final fracture, which might be caused by interfacial failure and progressive damage of the carbon fiber. The UTS is as high as $235 \mathrm{kN}$, which is almost twice of that of the aluminum specimen, indicating significant improvement in tensile capacity contributed by the composite layer. The structural discontinuity between the trap-lock section and the middle tubular section led to stress concentration and subsequent interfacial de-bonding and eventually final fracture failure as seen in Figure 8(b). Such interfacial

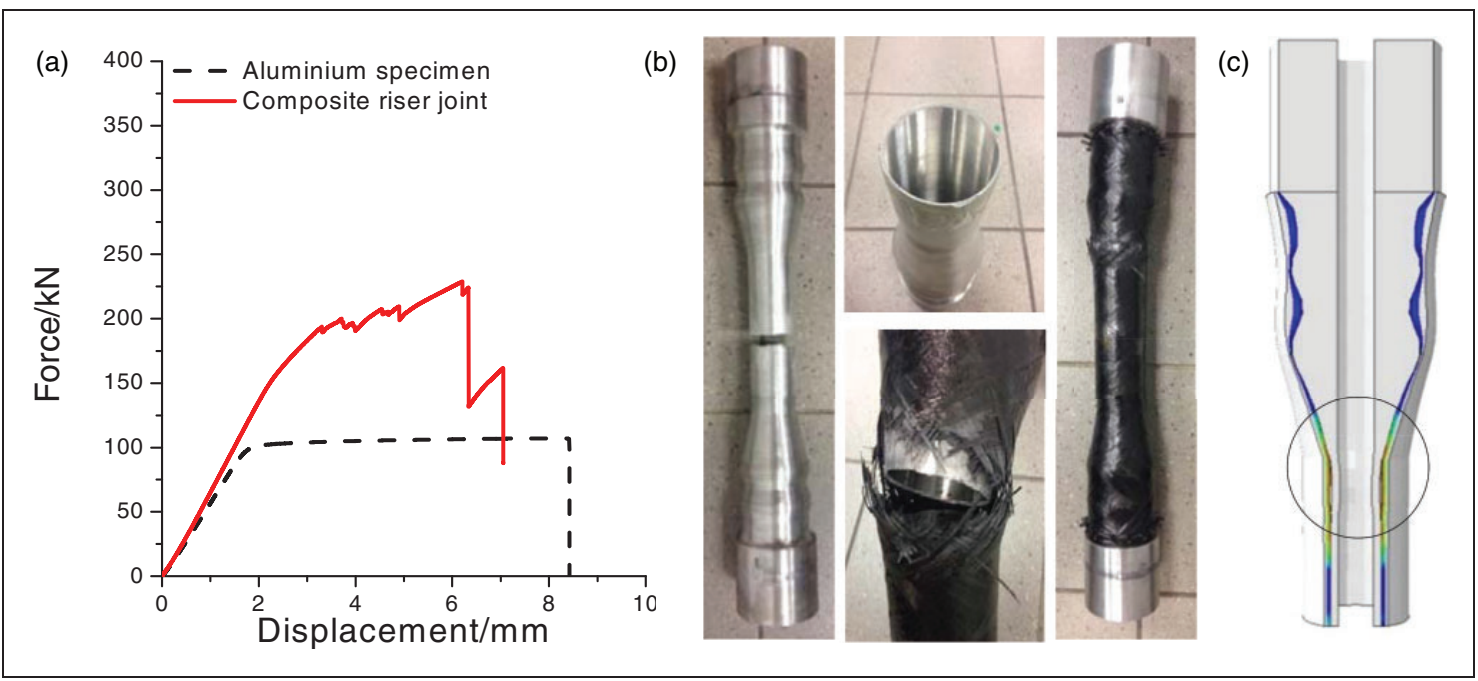

Figure 8. (a) Force-displacement curves of composite riser and aluminum mandrel, (b) failed specimens, and (c) interfacial debonding process as predicted from finite element analysis. 
de-bonding failure mechanism is well captured and verified in FE simulations as seen in Figure 8(c).

\section{Combined loading tests and failure envelopes}

In the combined loading tests, shear force is negated as described previously in the test with a high pretension of $150 \mathrm{kN}$, for which a relatively low bending moment is required to damage the specimen. Figure 9(a) and (b) shows the force history acting on the specimen as well as the axial displacement histories measured using a laser sensor and the Hexapod's internal displacement measurement system. The axial tension $F_{Z}$ increases to $150 \mathrm{kN}$ linearly within $50 \mathrm{~s}$ and is kept constant after that. The compliance of the test rig leads to a significant divergence of the internally and externally measured displacement signals. Therefore, only the external displacement signal is used for comparison between simulation and experimental results with regards to the global stiffness of the structure. Following the tensile load application, the Hexapod ring is inclined to exert a bending moment on the prototype. With the inclination, the external laser signals are lost. The laser system measures the axial deformation of the specimen by sending a beam from the base plate and sensing its reflection from mirrored surfaces attached to the Hexapod ring. When the ring is inclined, the mirrored surfaces also rotate and the lasers no longer reflect back to the sensors. In order to keep the shear force $F_{x}$ zero as described previously, the control system of the test rig has to compensate by laterally displacing the Hexapod ring during the inclination process. Figure 9(c) and (d) shows the bending moment measured by the load cell as well as the (a)

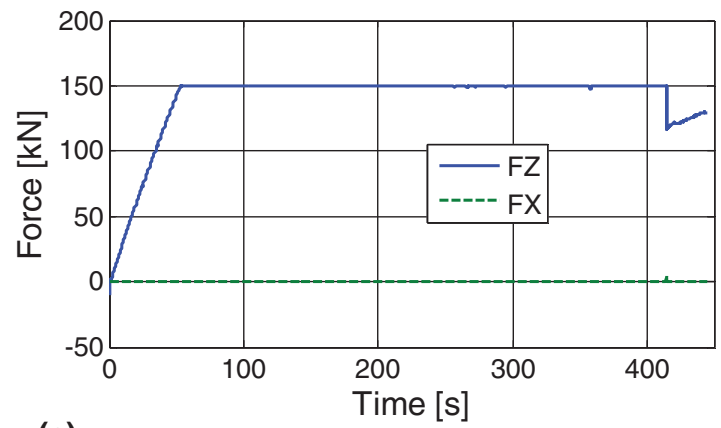

(c)

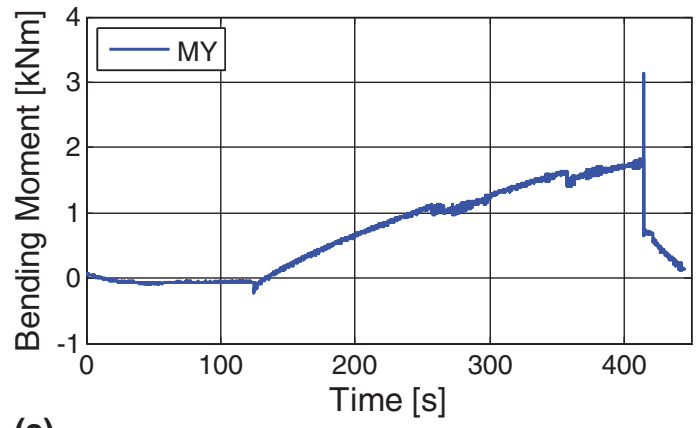

(e)

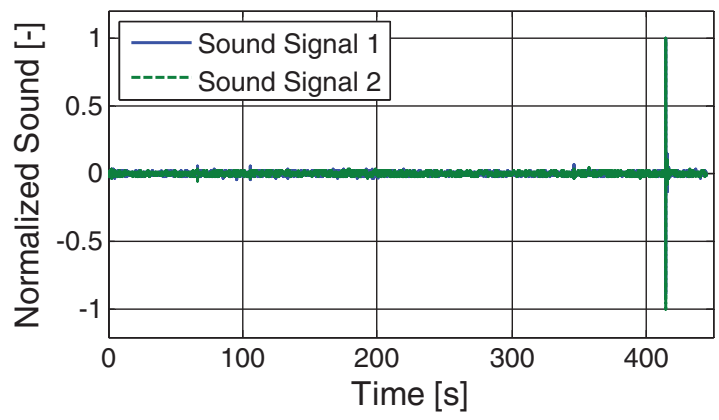

(b)

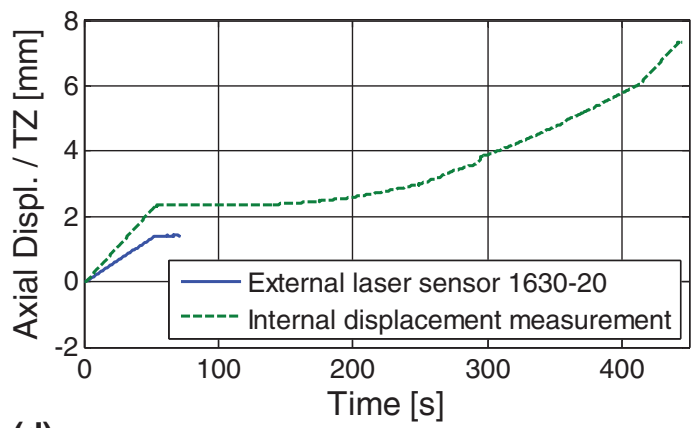

(d)
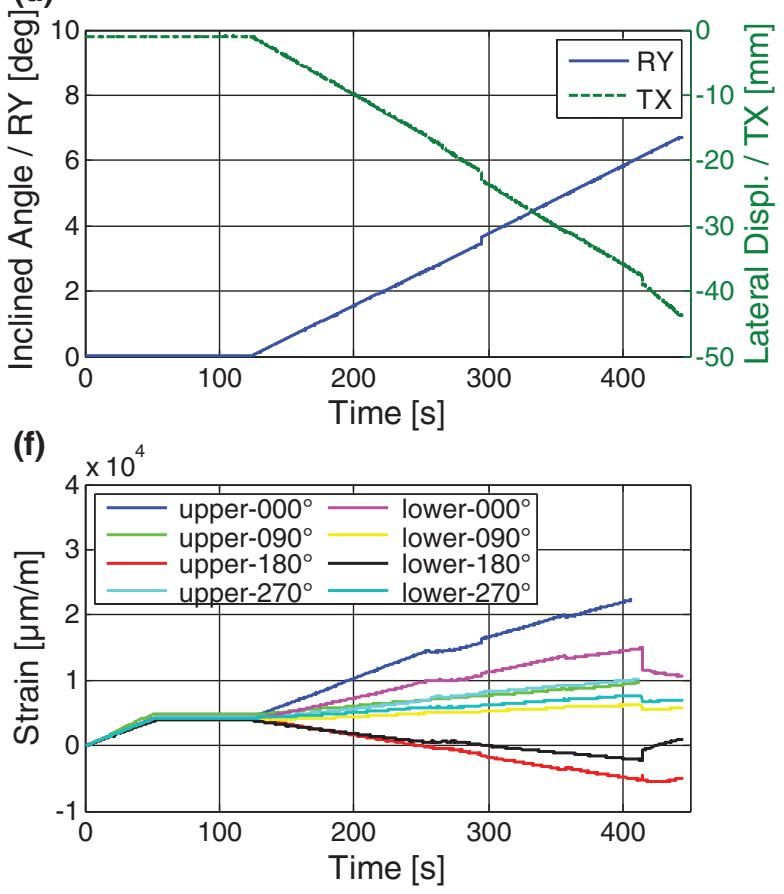

Figure 9. Experimental results of combined loading test with initial tension of $150 \mathrm{kN}$. 


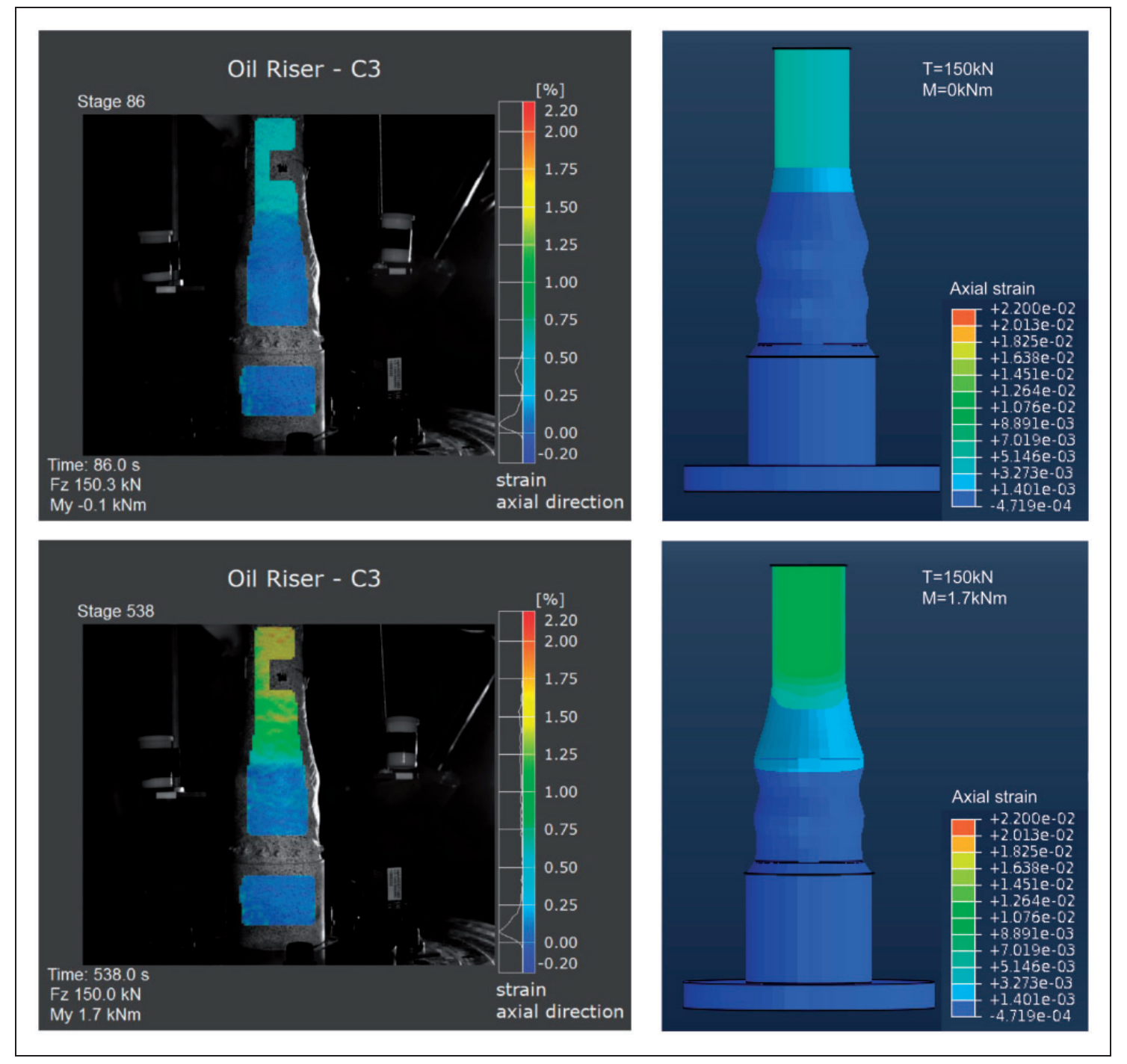

Figure 10. Comparison of axial strains measured by DIC and predicted by FEA.

inclination angle Ry and lateral displacement Tx of the Hexapod ring. The composite riser fails at a bending moment of about $1.7 \mathrm{kN}$ and an in situ inclination angle of $7^{\circ}$, which is approaching the machine limit of $8^{\circ}$. Figure 9(e) shows the acoustic signals recorded during the tests. The pulse toward the end of the recording captures the final rupture.

During the pure tensile loading stage, both, DIC and strain gauge measurement, indicate a strain of $0.4 \%$ at the middle section of the riser. This value is matched accurately by the FE-simulation (Figure 10, top). In case of the combined tensile-bending load, the DIC results show an inhomogeneous strain field on the surface of the middle section averaging about $1.5 \%$. This is comparable to the $1.44 \%$ strain measured by the strain gauge. The FE-simulation predicts a lower value of $1.2 \%$. This difference might be attributed to the uneven surface of the composite windings and the limited resolution of the DIC cameras. It is therefore more pronounced in the case of additional bending, leading to high strains on the riser front, which is under tensile stress.

For lower pretension loads, it is not possible to fail the specimens without any shear force because the machine is unable to generate sufficient bending moment due to the $8^{\circ}$ inclination limit. Hence, the Hexapod ring is inclined without any translation to negate shear forces. For the cases with pretension of 0,50 , and $100 \mathrm{kN}$, shear forces are nonzero. Figure 11 shows the experimental results for the case of $50 \mathrm{kN}$ pretension. Figure 11(a) shows the axial tension and lateral shear force measured by the load cell. The lateral shear force increases accordingly with inclination. As explained in "Combined loading tests using a six DOF test rig" section, the bending moment is greatest at the bottom of the specimen and 
(a)

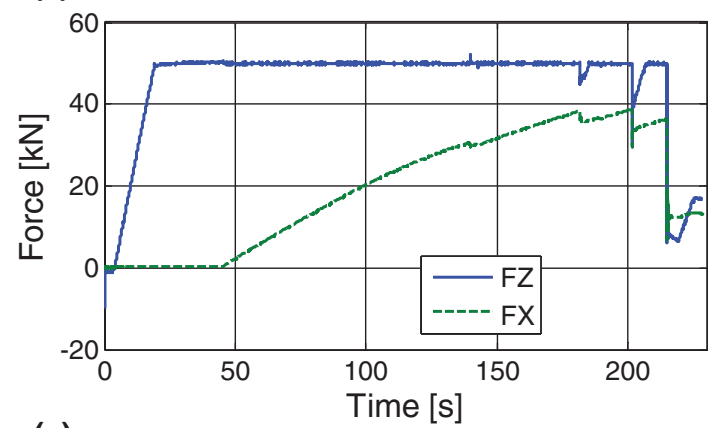

(c)

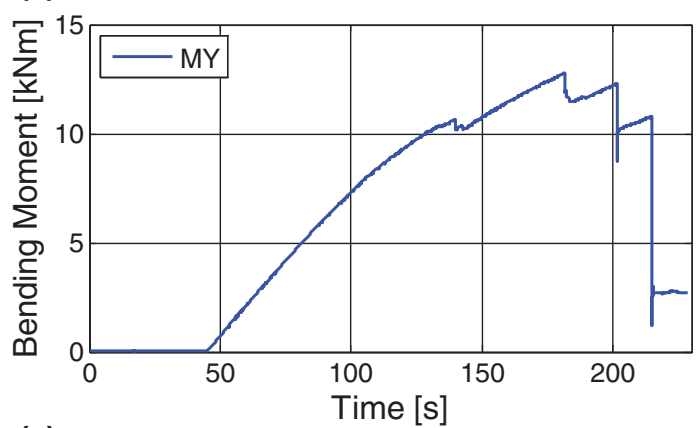

(e)

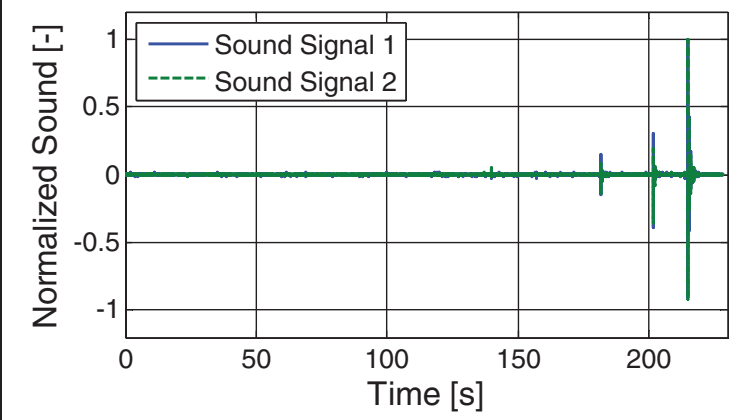

(b)

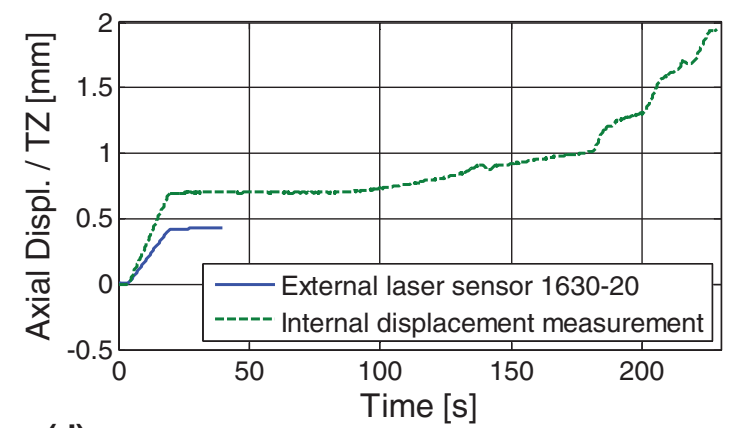

(d)

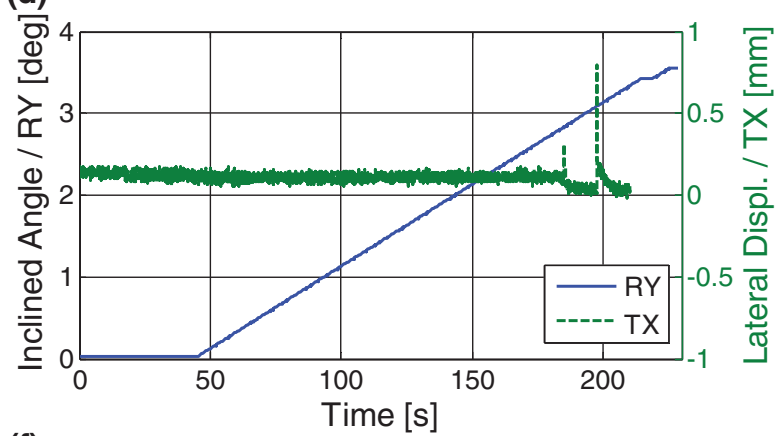

(f)

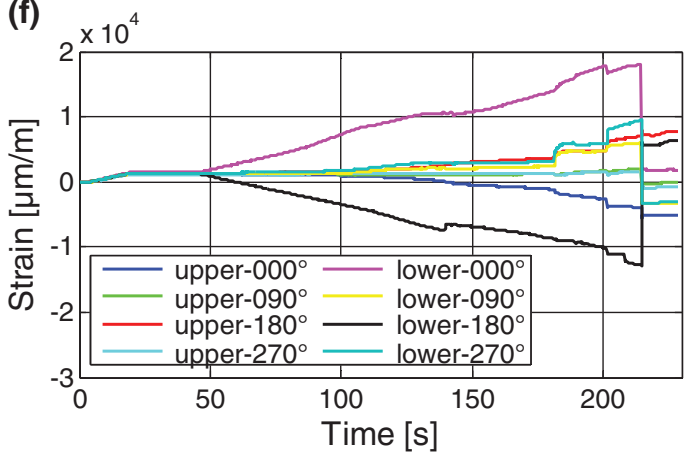

Figure II. Experimental results of combined loading test with initial tension of $50 \mathrm{kN}$.

is calculated from $M=M_{\text {bottom }}-F_{x} d$. Here, $M$ is the bending moment and $F_{x}$ is the lateral force measured at the load cell, while $d$ is distance between location of interest and the load cell. This is corroborated by the higher bending strains measured by the lower strain gauges compared to the upper ones (Figure 9 (f)). During the bending process, several small drops are observed for the bending moment. These drops correspond to signals captured by the microphones (Figure 11(e)). Such drops might be caused by interfacial failure, matrix cracking, or carbon fiber failure. However, it is difficult to distinguish the various failure modes using current measurement techniques.

A tension-bending failure envelope is plotted based on these combined loading tests to provide a quick evaluation of the structural performance following industrial codes. ${ }^{22}$ Figure 12(a) shows the failure envelopes of the composite riser prototype, including both experimental results and FE-predictions. In order to understand the influence of the trap-lock end fitting on the structural strength, the FE-predicted failure envelopes of a control group without end fittings are also presented and compared. The numerical predictions are in good agreement with experiments regarding the ultimate load values, demonstrating the robustness and accuracy of the FE model. Relatively fine elements are needed. Otherwise, the complex geometry at the trap-lock section would make the stress values sensitive to local meshes. The model with mesh size of $20 \mathrm{~mm}$ shows slight deviation while other models with mesh size smaller than 10-mm converge well. Mesh dependence is negligible for the tubular model without end fittings as expected due to its simple geometry. The failure envelope curve is expected to be linear for 


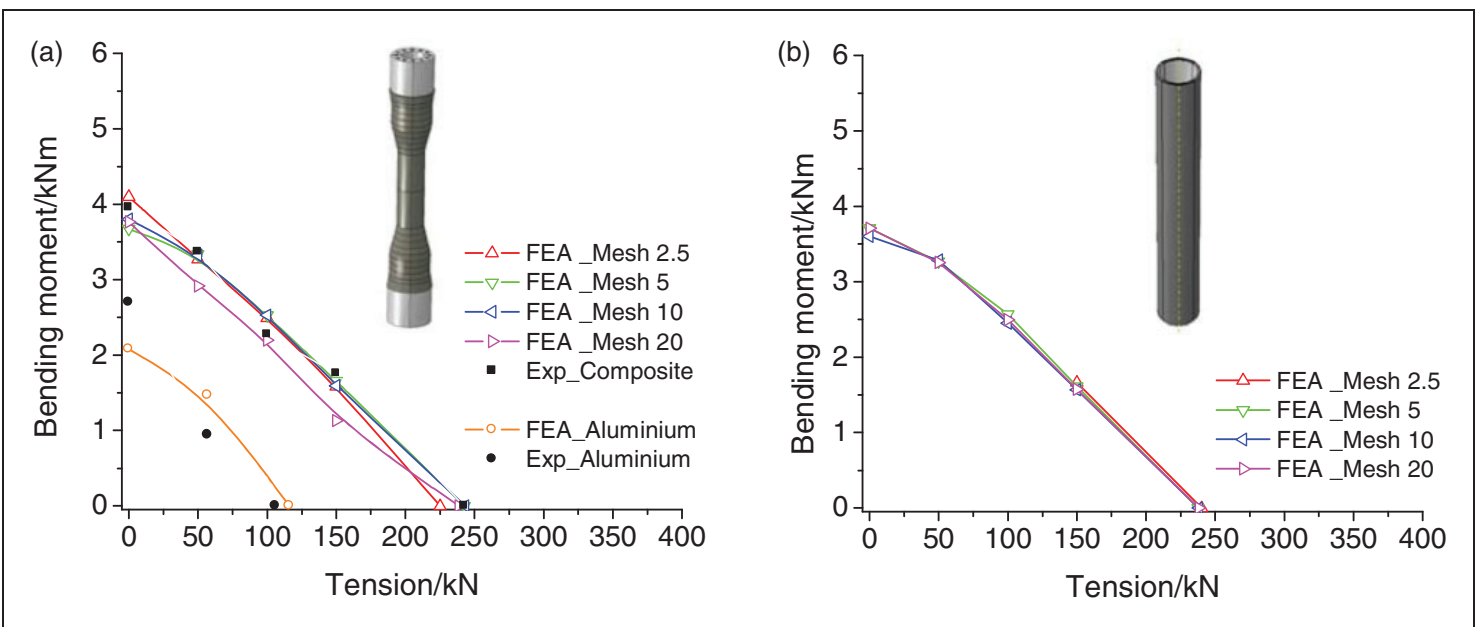

Figure I2. Tensile-bending failure envelopes of (a) composite riser joints and (b) a tubular model without end fitting.

(a)

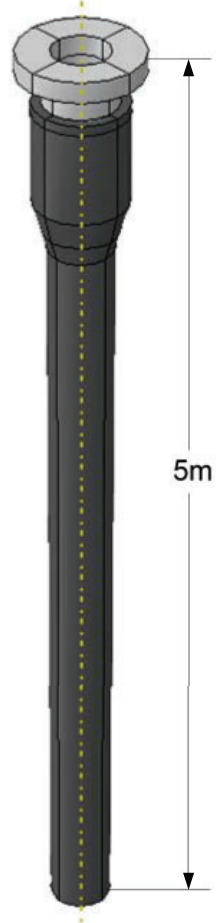

(b)

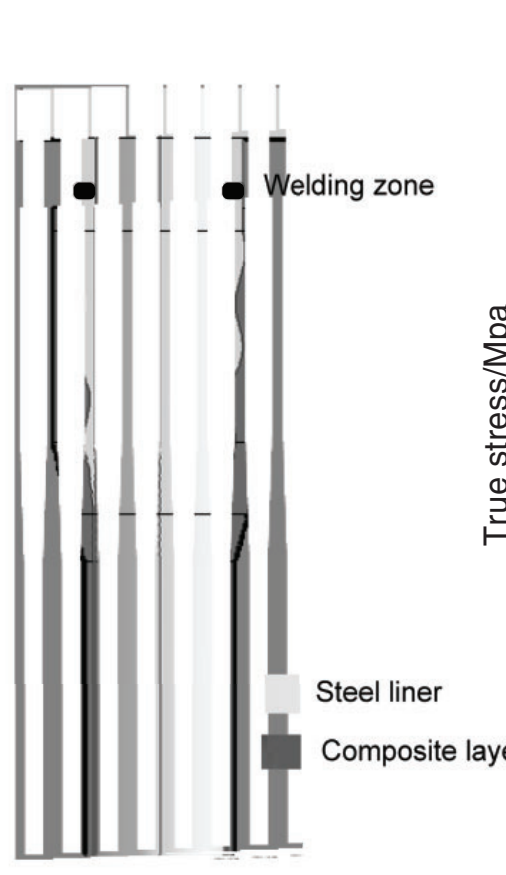

(c)

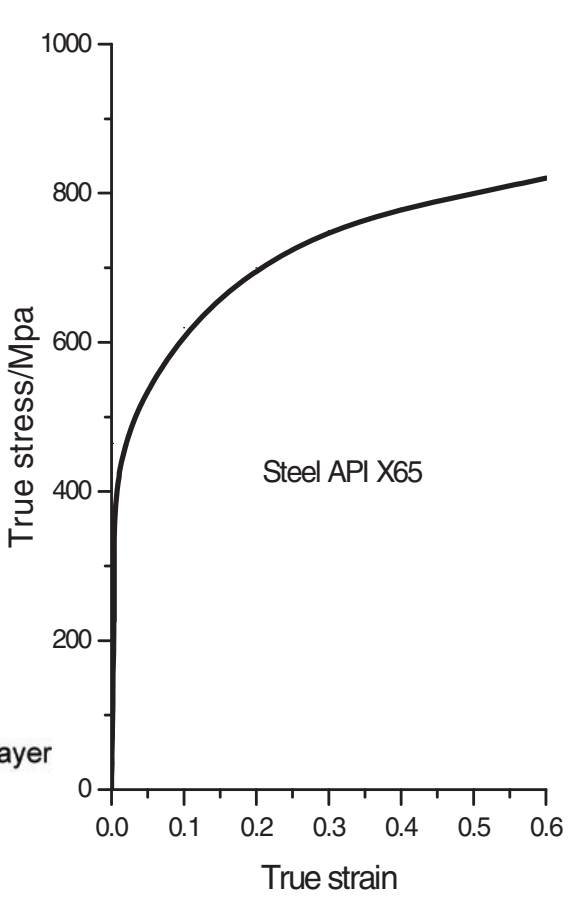

Figure 13. (a) Full-scale composite riser model, (b) geometry of trap-lock section, and (c) stress-strain curve of steel API X65. ${ }^{25}$

homogeneous and isotropic materials with the same tensile and compressive strengths. For the composite riser with complex geometry and two materials, the failure envelope curves are non-linear. In the cases of low initial tension, the bending moment required at the next step to fail the prototype is high. Such high bending moment will initiate compressive failure on one side prior to tensile failure on the other side because the compressive strength of CFRP is lower than its tensile strength as shown in Table 1. Conversely, when the initial tension is high, the bending moment required is relatively low. Tensile failure on one side of the riser will occur before the opposite side meets the criterion of compressive damage initiation. It is interesting to see the shift of the failure mechanism, which is controlled by the tension-bending ratio applied. 

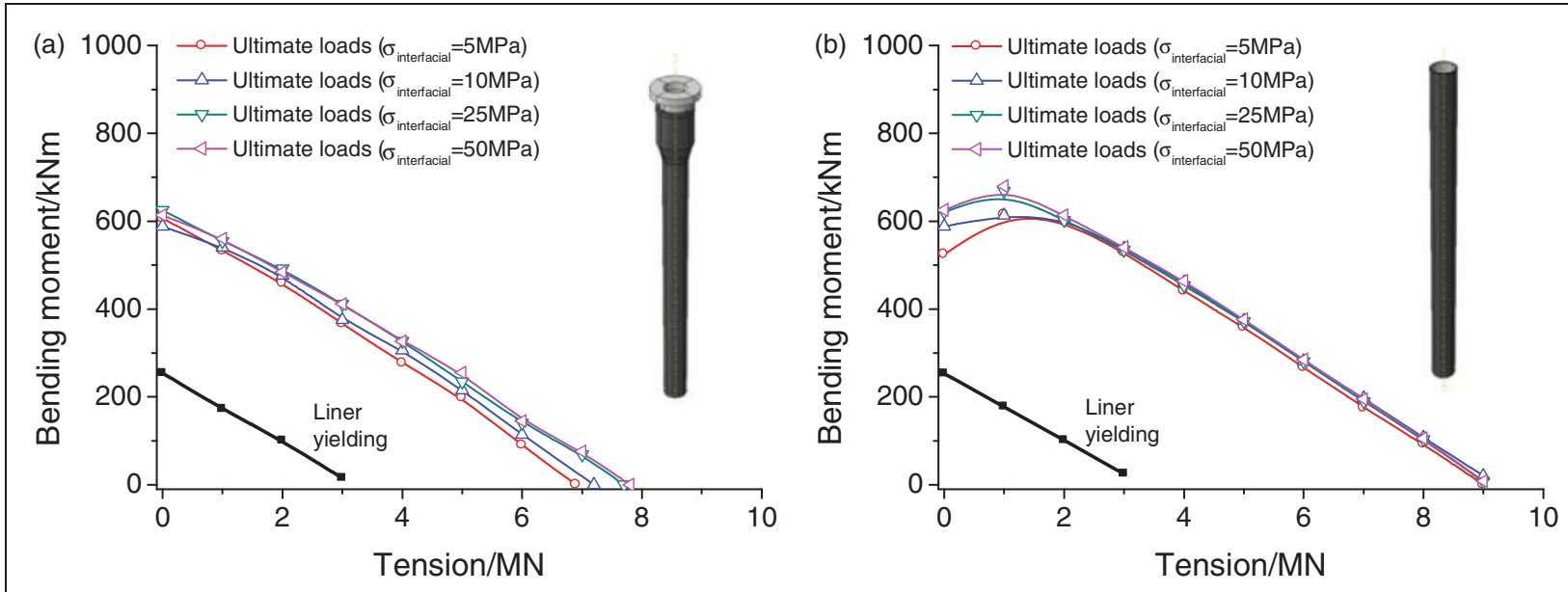

Figure 14. Tensile-bending failure envelopes of (a) a full-scale composite riser and (b) a tubular model without end fitting.

\section{Full-scale composite riser design}

The numerical model has been verified by the agreement of failure envelopes between FE predictions and experimental results. In this section, the FE framework will be extended to design and analysis of full-scale composite risers for performance prediction.

Figure 13 shows the model of a full-scale composite riser. The geometry comes from our previous work. ${ }^{23,24}$ The riser joint has an internal diameter of $0.2 \mathrm{~m}$ and a length of $10 \mathrm{~m}$. It is featured with a $5-\mathrm{mm}$ thick steel liner and a 15-mm thick composite layer. The composite layup is assumed to be the same as in the scaled-down prototype. Due to structural symmetry, only half of the prototype is modeled to reduce computational time.

Figure 14 shows the failure envelopes of the full-scale riser joint with various interfacial bonding strengths. A tubular model without end fitting is also studied for comparison. The following conclusions can be drawn. First, the steel liner in both models yields at an early stage. After yielding, the composite layer can still withstand substantially high tension and bending moment. Second, the non-linearity of the failure envelope curve due to two different failure modes explained in "Combined loading tests and failure envelopes" section is obvious in the tubular model, but not the joint model. Third, the tensile capacity of the joint model seems to be dependent on the interfacial strength. The stronger the interface is, the higher is the tensile capacity. However, such dependence is not obvious for bending capacity. For the tubular model, the situation reverses. The bending capacity rather than tensile capacity is seen to be dependent on interfacial strength. Finally, as seen in "Combined loading tests and failure envelopes" section, the scaleddown riser joint with end fitting shows comparable tensile-bending capacity with the tubular model. However, in the full-scale models, the tension-bending capacity of the joint model is below that of the tubular model, indicating negative size effect of the trap-lock section on structural performance. When scaling the riser joint, the wall thickness and interfacial area between metal liner and composite actually do not increase proportionally with the internal diameter. Therefore, the interfacial area at the trap-lock region might not be sufficient and strong enough in the full-scale model to ensure that the endfitting section is as strong as the middle tubular section resulting in a lower overall tensile-bending capacity.

\section{Conclusion}

The main conclusions are provided as follows:

Filament winding is a feasible technique for fabricating composite riser joints with trap-lock end fittings. The metallic mandrel will be left in the product, and it will play the role of a liner for anti-abrasion and liquid tightness. The metallic liner will bear considerable axial tension due to its high modulus and will yield at an earlier stage prior to composite failure. Therefore, soft yet strong materials would be promising for the liner if such material systems are available.

Substantial improvement in tensile-bending capacity is demonstrated by experiments on scale-down prototypes and predicted by a robust FE framework. The performance improvement comes from the high strength of CFRP.

For composite risers, the damage initiation site may shift from one side to the opposite, depending on the tension/bending moment ratio. Such shift is attributed to the low compressive strength and high tensile strength of CFRP materials.

Scale-down composite riser joints exhibit similar tensile-bending capacity with the tubular model, suggesting that the trap-lock end fitting is equally strong with the middle tubular section. However, numerical analysis on a 
full-scale model shows that the overall tensile-bending capacity is lowered by the trap-lock end fitting because of size effects.

Both interfacial strength and wall thickness/ID ratio would affect the performance of the trap-lock end fitting. Further research would focus on establishing a quantitative correlation between these design variables by experiments and parametric studies with the help of optimization packages.

\section{Declaration of Conflicting Interests}

The author(s) declared no potential conflicts of interest with respect to the research, authorship, and/or publication of this article.

\section{Funding}

The author(s) disclosed receipt of the following financial support for the research, authorship, and/or publication of this article: The authors gratefully acknowledge the support from Singapore Agency for Science, Technology and Research (project no. 1123004033) and the Singaporean-German Mobility Programme (project no. SGP-PROG-060).

\section{References}

1. Howells $\mathrm{H}$ and Hatton SA. Challenges for ultra-deep water riser systems. 2H Offshore Engineering Limited, 1997.

2. Alexander C, Vyvial B, Cedergery C, et al. Evaluating the performance of a composite-reinforced steel drilling riser via full-scale testing for HPTH service. In: Proceedings of the 6 th international offshore pipeline forum, Houston, TX, 19-20 October 2011, paper no. IOPF2011-4002.

3. Salama MM. Some challenges and innovations for deepwater developments. In: Offshore technology conference, Houston, TX, 5 May 1997, paper no. OTC-8455-MS.

4. Hatton S, Rumsey L, Biragoni P, et al. Development and qualification of end fittings for composite riser pipe. In: Offshore technology conference, Houston, TX, 6-9 May 2013, paper no. OTC 23977-MS.

5. Sparks CP and Odru P. Mechanical testing of high-performance composite tubes for TLP production risers. In: Offshore technology conference, Houston, TX, 2 May 1988, paper no. OTC 5797-MS.

6. Sparks CP and Odru P. Composite riser tubes: defect tolerance assessment and non-destructive testing. In: Offshore technology conference, Houston, TX, 4 May 1992, paper no. OTC 6894-MS.

7. Baldwin DD and Newhouse NL. Composite production riser design. In: Offshore technology conference, Houston, TX, 5 May 1997, paper no. OTC-8431-MS.

8. Drey MD, Salama MM, Long JR, et al. Composite production riser-testing and qualification. Society of petroleum engineers. 1 August 1998, 13. DOI: 10.2118/50971-PA.

9. Andersen WF, Anderson JJ, Mickelson CS, et al. The application of advanced composite technology to marine drilling riser systems: design, manufacturing and test. In: Offshore technology conference, Houston, TX, 5 May 1997, paper no. OTC 8433-MS.
10. Adersen WF, Anderson JJ and Landriault LS. Full-scale testing of prototype composite drilling riser joints-interim report. In: Offshore technology conference, Houston, TX, 4 May 1998, paper no. OTC 8668-MS.

11. Baldwin DD, Drey MD and Reigle JA. Interface system between composite tubing and end fittings. Patent US 6042152 A, USA, 1997.

12. Salama MM, Stjern G, Storhaug T, et al. The first offshore field installation for a composite riser joint. In: Offshore technology conference, Houston, TX, 6 May 2002, paper no. OTC 14018-MS.

13. Orchoa OO. Composite Riser Experience and Design Guidance (prepared for MMS as a guideline for composite offshore engagements), Offshore Technology Research Centre, Texas A\&M University, 1435-01-04ca-35515, MMS Prof No 490.

14. Ramirez G and Engelhardt MD. Experimental invesitgation of a large-scale composite riser tube under external pressure. J Pressure Vessel Technol 2009; 131: 051205.

15. Material Safety Data Sheet of Epicote 1002 FW, Polymer Technologies Pte Ltd, Singapore.

16. Schillo C, Röstermundt D and Krause D. Experimental and numerical study on the influence of imperfections on the buckling load of unstiffened CFRP shells. Composite Struct 2015; 131: 128-138.

17. Ambriz RR, Mesmacque G, Benhamena A, et al. Fatigue crack growth behavior in 6061-T6 aluminum alloy welds obtained by MIEA. Sci Technol Welding Joining 2010; 15: 514-521.

18. Abaqus 6.13 Analysis User's Manual, SIMULIA, Dassault System.

19. Davies P, Sohier L, Cognard JY, et al. Influence of adhesive bond line thickness on joint strength. Int $J$ Adhes Adhes 2009; 29: 724-736.

20. Hashin Z. Failure criteria for unidirectional fiber composites. J Appl Mech 1980; 47: 329-334.

21. Bakaiyan H, Hosseini H and Ameri E. Analysis of multilayered filament-wound composite pipes under combined internal pressure and thermomechanical loading with thermal variations. Composite Struct 2009; 88: 532-541.

22. DNV-RP-F202: Composite risers.

23. Chen Y, Tan LB, Jaiman RK, et al. Global-local analysis of a full-scale composite riser during vortex-induced vibration (VIV). In: Proceedings of the ASME 32nd international conference on ocean, offshore and arctic engineering, Nantes, 2013.

24. Tan LB, Chen Y, Jaiman RK, et al. Coupled fluidstructure simulations for evaluating the performance of full-scale deepwater composite risers. J Ocean Eng 2015; 94: 19-35.

25. Oh CK, Kim YJ, Baek JH, et al. Ductile failure analysis of API X65 pipe with notch-type defects using a local fracture criterion. Int J Pressure Vessel Piping 2007; 84: 512-525.

26. Mintzas A, Hatton S, Simandjuntak S, et al. An integrated approach to the design of high performance carbon fibre reinforced risers-from Micro to Macro-scale; Deep Offshore Technology International, Houston, TX, 2013. 